\title{
Nitrogen Availability Affects the Metabolic Profile in Cyanobacteria
}

\author{
Kosuke Inabe ${ }^{1}{ }^{1}$, Ayaka Miichi $^{2}$, Mami Matsuda ${ }^{2}$, Takanobu Yoshida ${ }^{2}$, Yuichi Kato ${ }^{1}{ }^{\circledR}$, Ryota Hidese ${ }^{2}$, \\ Akihiko Kondo ${ }^{1,2,3}$ and Tomohisa Hasunuma 1,2,* \\ 1 Innovation and Technology and Engineering Biology Research Center, Kobe University, Nada, \\ Kobe 657-8501, Japan; inabe@people.kobe-u.ac.jp (K.I.); yuichi@shark.kobe-u.ac.jp (Y.K.); \\ akondo@kobe-u.ac.jp (A.K.) \\ 2 Graduate School of Science, Innovation and Technology, Kobe University, Nada, Kobe 657-8501, Japan; \\ ayaka.miichi@gmail.com (A.M.); matsuda_mami@harbor.kobe-u.ac.jp (M.M.); \\ t-yoshida@port.kobe-u.ac.jp (T.Y.); hidese@people.kobe-u.ac.jp (R.H.) \\ 3 Department of Chemical Science and Engineering, Graduate School of Engineering, Kobe University, Nada, \\ Kobe 657-8501, Japan \\ * Correspondence: hasunuma@port.kobe-u.ac.jp; Tel.: +81-78-803-6461
}

check for updates

Citation: Inabe, K.; Miichi, A.; Matsuda, M.; Yoshida, T.; Kato, Y.; Hidese, R.; Kondo, A.; Hasunuma, T. Nitrogen Availability Affects the Metabolic Profile in Cyanobacteria. Metabolites 2021, 11, 867. https: / / doi.org/10.3390/metabo11120867

Academic Editor: Pawel Lorkiewicz

Received: 2 December 2021

Accepted: 10 December 2021

Published: 14 December 2021

Publisher's Note: MDPI stays neutral with regard to jurisdictional claims in published maps and institutional affiliations.

Copyright: (c) 2021 by the authors. Licensee MDPI, Basel, Switzerland. This article is an open access article distributed under the terms and conditions of the Creative Commons Attribution (CC BY) license (https:/ / creativecommons.org/licenses/by/ $4.0 /)$.

\begin{abstract}
Nitrogen is essential for the biosynthesis of various molecules in cells, such as amino acids and nucleotides, as well as several types of lipids and sugars. Cyanobacteria can assimilate several forms of nitrogen, including nitrate, ammonium, and urea, and the physiological and genetic responses to these nitrogen sources have been studied previously. However, the metabolic changes in cyanobacteria caused by different nitrogen sources have not yet been characterized. This study aimed to elucidate the influence of nitrate and ammonium on the metabolic profiles of the cyanobacterium Synechocystis sp. strain PCC 6803. When supplemented with $\mathrm{NaNO}_{3}$ or $\mathrm{NH}_{4} \mathrm{Cl}$ as the nitrogen source, Synechocystis sp. PCC 6803 grew faster in $\mathrm{NH}_{4} \mathrm{Cl}$ medium than in $\mathrm{NaNO}_{3}$ medium. Metabolome analysis indicated that some metabolites in the CBB cycle, glycolysis, and TCA cycle, and amino acids were more abundant when grown in $\mathrm{NH}_{4} \mathrm{Cl}$ medium than $\mathrm{NaNO}_{3}$ medium. ${ }^{15} \mathrm{~N}$ turnover rate analysis revealed that the nitrogen assimilation rate in $\mathrm{NH}_{4} \mathrm{Cl}$ medium was higher than in $\mathrm{NaNO}_{3}$ medium. These results indicate that the mechanism of nitrogen assimilation in the GS-GOGAT cycle differs between $\mathrm{NaNO}_{3}$ and $\mathrm{NH}_{4} \mathrm{Cl}$. We conclude that the amounts and biosynthetic rate of cyanobacterial metabolites varies depending on the type of nitrogen.
\end{abstract}

Keywords: cyanobacteria; nitrogen; metabolome; photosynthesis

\section{Introduction}

Nitrogen is an important element for living things, being used in amino acids, nucleotides, lipids, and sugars, which are building blocks of all forms of life. Cyanobacteria are Gram-negative bacteria and are known to be oxygenic photosynthetic microorganisms that utilize solar energy to generate chemical energy (ATP and NADPH). Such chemical energy is used in the Calvin-Benson-Bassham cycle (CBB cycle), glycolysis, and tricarboxylic acid (TCA cycle). Similar to other organisms, non-diazotrophic cyanobacteria, such as Synechocystis sp. PCC 6803 can take up nitrogen as $\mathrm{NO}_{3}{ }^{-}, \mathrm{NO}_{2}{ }^{-}, \mathrm{NH}_{4}{ }^{+}, \mathrm{CO}\left(\mathrm{NH}_{2}\right)_{2}$ (urea), and arginine [1,2]. Diazotrophic cyanobacteria (for example, Anabaena sp. PCC 7120) can fix $\mathrm{N}_{2}$ in heterocyst cells using nitrogenase [3]. Cyanobacteria require reducing power when using the former nitrogen sources $\left(\mathrm{NO}_{3}{ }^{-}\right.$and $\left.\mathrm{NO}_{2}{ }^{-}\right)$, but not when using the latter $\left(\mathrm{NH}_{4}{ }^{+}\right.$, urea, and arginine). $\mathrm{NO}_{3}{ }^{-}$and $\mathrm{NO}_{2}{ }^{-}$transporters are already identified as NrtA-D. $\mathrm{NH}_{4}{ }^{+}$is transported by ammonium transporters Amt1-3 and urea by urea transporters UrtA-E [4-6]. $\mathrm{NO}_{3}{ }^{-}$in the cell is reduced to $\mathrm{NO}_{2}{ }^{-}$by ferredoxin-nitrate reductase, $\mathrm{NarB}$, and finally reduced to $\mathrm{NH}_{4}{ }^{+}$by NirA $[7,8]$. Urea in the cell is converted by UreA-B to $\mathrm{NH}_{3}[6,9]$. $\mathrm{NH}_{4}{ }^{+}$is produced from arginine by arginine dihydrolase [2]. The 
GS (glutamine synthetase)-GOGAT (glutamate synthase or glutamine-oxoglutarate cycle amido transferase) cycle synthesizes glutamate and glutamine from $\mathrm{NH}_{4}{ }^{+}$and 2OG [10]. The resulting Glu is mainly consumed as a nitrogen source.

Although cyanobacteria can assimilate nitrogen compounds as mentioned above, the choice of nitrogen sources is important for cultivation because photosynthesis and growth are affected by the type of nitrogen source [11-13]. In addition, there are differences in gene expression associated with utilizing the nitrogen sources and changes in activity of enzymes involved in nitrogen assimilation when cyanobacteria are exposed to each of the nitrogen sources, $\mathrm{NO}_{3}{ }^{-}, \mathrm{NH}_{4}{ }^{+}$, and urea [14-16]. The physiological response of cyanobacteria to nitrogen sources also varies according to the species $[13,17]$. We previously reported that when Synechocystis sp. PCC 6803 was phototrophically cultivated in the presence of $\mathrm{NH}_{4} \mathrm{Cl}$, it produced a higher content of intracellular organic acids including malate, fumarate, and succinate under dark anoxic fermentation than cells grown in $\mathrm{NaNO}_{3}$, resulting in increased succinate secretion [18]. In this way, the influences of different types of nitrogen sources have been investigated to reveal the physiological responses of cyanobacteria and their application. However, metabolites produced with different types of nitrogen sources have not been fully investigated, in contrast to the effects of nitrogen starvation $[19,20]$. Moreover, in our previous report, we revealed that the different metabolic profiles produced during dark anoxic cultivation after a transfer from phototrophic cultivation with different nitrogen sources enhanced the production of succinate. These findings prompted us to investigate the metabolic profiles under phototrophic conditions.

In this study, we aimed to clarify the metabolic responses to different nitrogen sources. For this purpose, we performed a combination of in vivo ${ }^{15} \mathrm{~N}$-labeling of metabolites and metabolome analysis. The ${ }^{15} \mathrm{~N}$-labeling technique is applied to detect metabolites of interest in cyanobacteria or to examine the metabolic behavior of a few metabolites $[2,17,21,22]$. This technique enables us to compare the metabolic turnover under different nitrogen sources by calculating the ${ }^{15} \mathrm{~N}$ labeling rate at each time point. Using this technique and metabolome analysis, we compared the metabolic profiles and synthesis rates of amino acids in Synechocystis sp. PCC 6803 when grown in $\mathrm{NaNO}_{3}$ or $\mathrm{NH}_{4} \mathrm{Cl}$, revealing distinct metabolic profiles between the different nitrogen sources.

\section{Results}

\subsection{Growth in Different Types of Nitrogen Source}

Synechocystis sp. PCC 6803 (hereafter Synechocystis) was cultivated in BG11 medium with $5 \mathrm{mM} \mathrm{NaNO}$ or $\mathrm{NH}_{4} \mathrm{Cl}$ (hereafter $\mathrm{NaNO}_{3}$ medium or $\mathrm{NH}_{4} \mathrm{Cl}$ medium) under phototrophic growth conditions (Figures 1 and S1). The growth rate of Synechocystis was also calculated based on the growth data by $48 \mathrm{~h}$ when there are the residual nitrogen sources. The growth rate of Synechocystis grown in $\mathrm{NaNO}_{3}$ medium or $\mathrm{NH}_{4} \mathrm{Cl}$ medium was $0.028 \pm 0.002 \mathrm{~h}^{-1}$ and $0.036 \pm 0.002 \mathrm{~h}^{-1}$. The growth rate of Synechocystis in $\mathrm{NH}_{4} \mathrm{Cl}$ medium was significantly faster than that in $\mathrm{NaNO}_{3}$ medium throughout the cultivation. In contrast, there was no significant difference in the residual amounts of $\mathrm{NaNO}_{3}$ and $\mathrm{NH}_{4} \mathrm{Cl}$ in either medium.

\subsection{Metabolome Analysis with Different Types of Nitrogen Source}

As nitrogen is thought to be assimilated mainly through the GS-GOGAT cycle, which synthesizes glutamate (Glu) and glutamine (Gln) from $\mathrm{NH}_{4}{ }^{-}$and $2 \mathrm{OG}$, we first compared the amino acid levels with different nitrogen sources (Figures 2 and S2). The pool sizes of serine (Ser), glycine (Gly), threonine (Thr), alanine (Ala), aspartate (Asp), asparagine (Asn), lysine (Lys), valine (Val), and isoleucine (Ile) when grown in $\mathrm{NH}_{4} \mathrm{Cl}$ medium were higher than those in $\mathrm{NaNO}_{3}$ medium $24 \mathrm{~h}$ after the start of cultivation. The pool sizes of methionine (Met) were still high $48 \mathrm{~h}$ after the start of cultivation. The pool sizes of Gln and Glu were the same between the $\mathrm{NaNO}_{3}$ and $\mathrm{NH}_{4} \mathrm{Cl}$ media. On the other hand, the pool size of tryptophan (Trp) when grown in $\mathrm{NH}_{4} \mathrm{Cl}$ medium was lower than that in $\mathrm{NaNO}_{3}$. 
Since Thr and Lys are synthesized from Asp, the pool sizes of Thr and Lys increased with an increase in Asp.

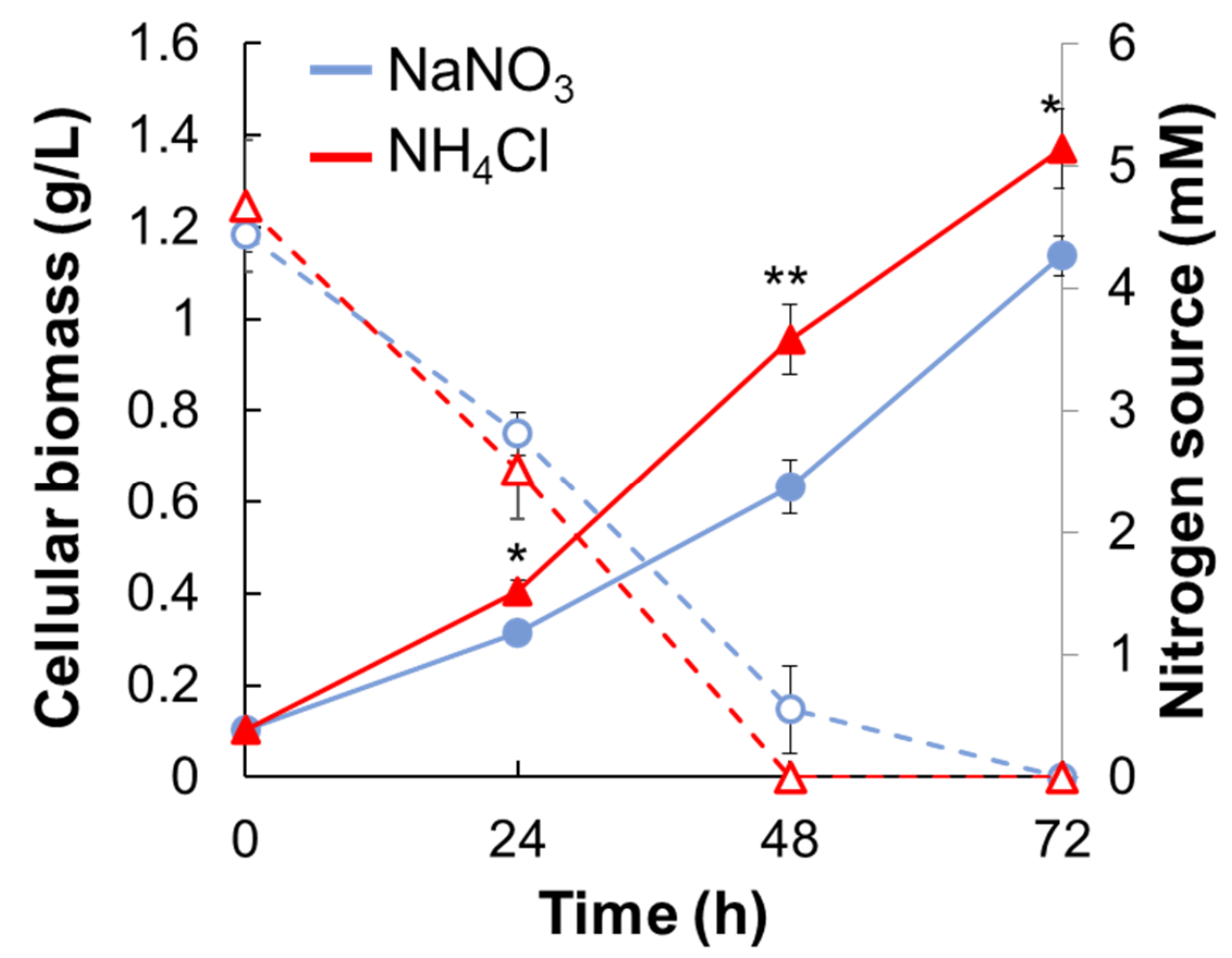

Figure 1. Cell growth of Synechocystis and the residual nitrogen concentration under different types of nitrogen. The cell growth of Synechocystis cultivated in $\mathrm{NaNO}_{3}$ medium or $\mathrm{NH}_{4} \mathrm{Cl}$ medium under phototrophic conditions was compared. Blue lines, $\mathrm{NaNO}_{3}$ medium; red lines, $\mathrm{NH}_{4} \mathrm{Cl}$ medium; solid lines, the cellular biomass (dried cell weight); dotted lines, the residual nitrogen concentration in the medium. Error bars indicate the standard deviation of three replicate experiments. Statistical significance was determined using Welch's $t$-test $\left({ }^{*}<0.05,{ }^{* *}<0.01\right)$.

To understand why the differences in amino acid levels occur, we also examined some metabolites of the CBB cycle, glycolysis, and TCA cycle (Figure 3). After $24 \mathrm{~h}$ from the start of cultivation, the levels of ribulose-1,5-bisphosphate (RuBP), 3-phosphoglycerate (3PGA), phosphoenolpyruvate (PEP), acetyl-coenzyme A (Ac-CoA), citrate (Cit), aconite (Aco), isocitrate (Isocit), and fumarate (Fum) were higher, and sedoheptulose 7-phosphate (S7P) and ribose 5-phosphate (R5P) were lower than those with $\mathrm{NaNO}_{3}$. In contrast, no difference was observed in the pool size of pyruvate (Pyr), although PEP, Ile, Val, and acetyl-CoA were increased. We speculate that Pyr synthesized from PEP may be immediately converted to Val, Ile, and Ac-CoA. 


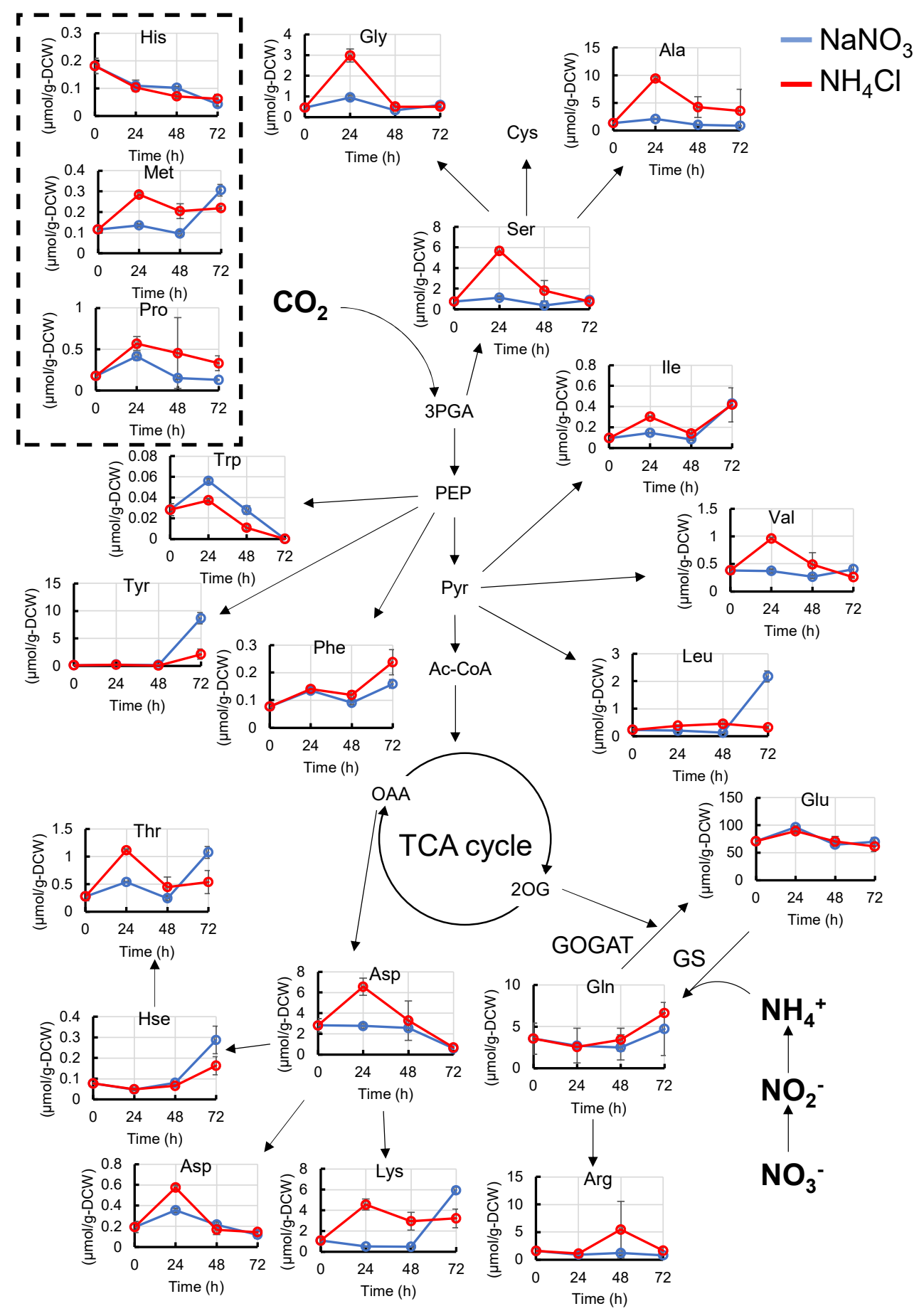

Figure 2. Metabolic profiles (amino acids) of Synechocystis cultured with $\mathrm{NaNO}_{3}$ or $\mathrm{NH}_{4} \mathrm{Cl}$. The abundance of amino acids when Synechocystis was cultivated in $\mathrm{NaNO}_{3}$ medium or $\mathrm{NH}_{4} \mathrm{Cl}$ medium were compared at each time point. Error bars indicate the standard deviation of three replicate experiments. Blue lines, cultivation in $\mathrm{NaNO}_{3}$ medium; red lines, cultivation in $\mathrm{NH}_{4} \mathrm{Cl}$ medium. 3PGA, 3-phosphoglycerate; Ac-CoA, acetyl-CoA; Ala, alanine; Arg, arginine; Asp, aspartate; Asn, asparagine; Cys, cysteine; Glu, glutamate; Gln, glutamine; His, histidine; Hse, homoserine; Ile, isoleucine; Leu, leucine; Met, methionine; PEP, phosphoenolpyruvate; Phe, phenylalanine; Pro, proline; Pyr, pyruvate; Ser, serine; Thr, threonine; Trp, tryptophan; Tyr, tyrosine; Val, valine. 


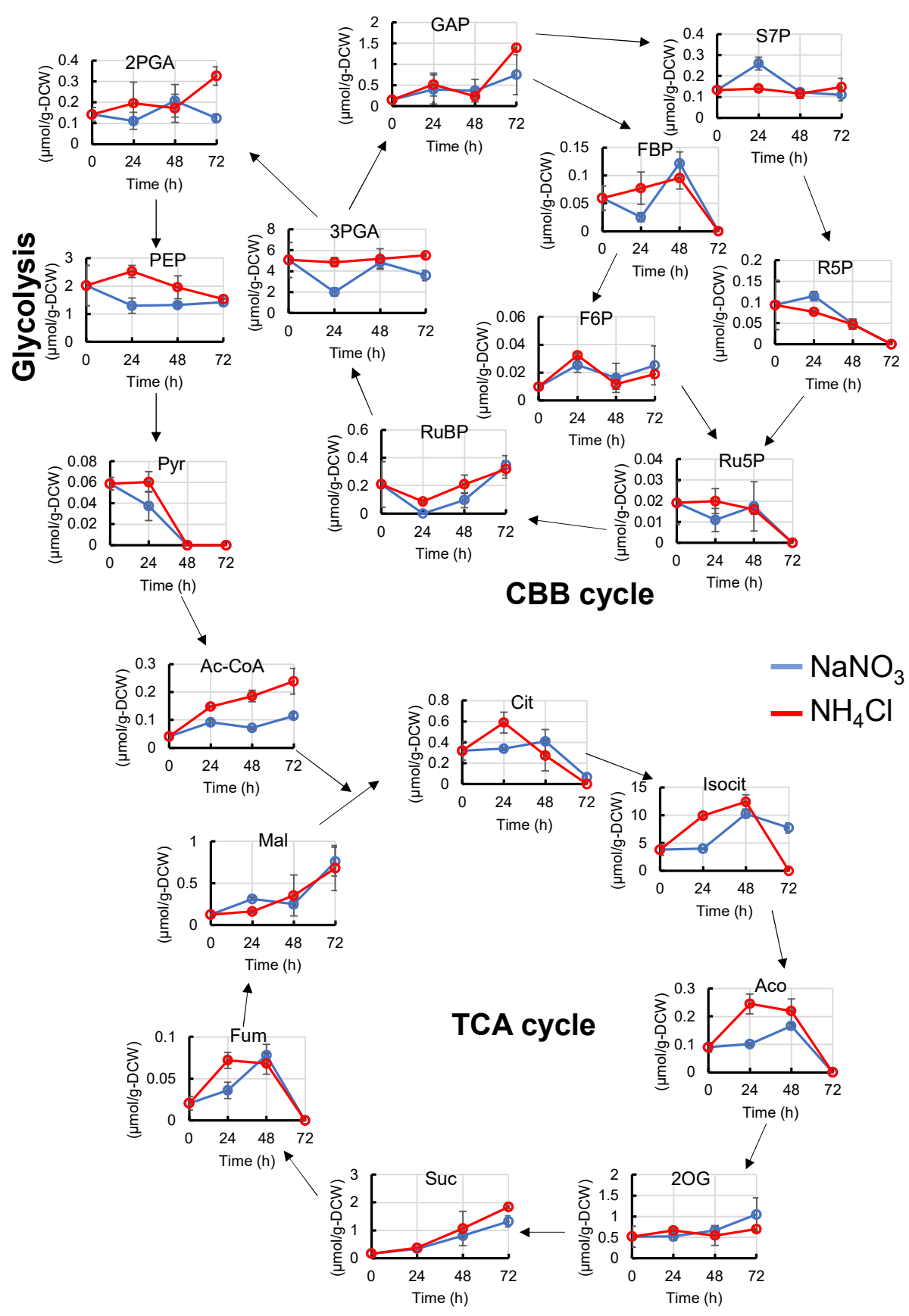

Figure 3. Metabolic profiles (CBB cycle, glycolysis and TCA cycle) of Synechocystis cultured with $\mathrm{NaNO}_{3}$ or $\mathrm{NH}_{4} \mathrm{Cl}$. The abundance of some metabolites in the CBB cycle, glycolysis, and TCA cycle were compared at each time point. Error bars indicate the standard deviation of three replicate experiments. Blue lines, cultivation with $\mathrm{NaNO}_{3}$; red lines, cultivation with $\mathrm{NH}_{4} \mathrm{Cl}$. 2PGA, 2-phosphoglycerate; 2OG, 2-oxoglutarate; 3PGA, 3-phosphoglycerate; Ac-CoA, acetyl-Coenzyme A; Cit, Citrate; F6P, fructose 6-phosphate; FBP, fructose 1,6-phosphate; Fum, fumarate; GAP, glyceraldehyde 3-phosphate; Isocit, isocitrate; PEP, phosphoenolpyruvate; Pyr, pyruvate; R5P, ribose 5-phosphate; Ru5P, ribulose 5-phosphate; RuBP, ribulose 1,5-bisphosphate; S7P, sedoheptulose 7 phosphate; Suc, succinate.

\section{3. ${ }^{15}$ N-Turnover Analysis with Different Types of Nitrogen}

The growth rates and pool sizes of the metabolites were different in $\mathrm{NaNO}_{3}$ and $\mathrm{NH}_{4} \mathrm{Cl}$. However, the nitrogen flow in the cell when grown in $\mathrm{NaNO}_{3}$ or $\mathrm{NH}_{4} \mathrm{Cl}$ media remains unclear. To reveal nitrogen flow with different nitrogen sources, we measured 
the time-resolved labeling rate of amino acids by ${ }^{15} \mathrm{~N}$ stable isotope labeling (Figure 4 and Figure S3). For this purpose, Synechocystis cells were taken after $24 \mathrm{~h}$ of cultivation and transferred to fresh BG11 medium containing ${ }^{15} \mathrm{NH}_{4} \mathrm{Cl}$ or $\mathrm{Na}^{15} \mathrm{NO}_{3}$ (labeling time $=0 \mathrm{~h}$ ). The labeling rates of Ala, Ser, and Gly, which are synthesized from 3PGA, were significantly higher in $\mathrm{NH}_{4} \mathrm{Cl}$ medium than in $\mathrm{NaNO}_{3}$ medium. The larger pool sizes of Ala, Ser, and Gly when Synechocystis are grown in $\mathrm{NH}_{4} \mathrm{Cl}$ medium might result from the higher ${ }^{15} \mathrm{~N}$ labeling rate. The labeling rate of Glu and Gln were significantly higher in $\mathrm{NH}_{4} \mathrm{Cl}$ medium than in $\mathrm{NaNO}_{3}$ medium, which is consistent with a previous report [17]. However, the pool sizes of Glu and Gln did not change, as shown in Figure 2. This indicates that when Synechocystis is grown in $\mathrm{NaNO}_{3}$ medium, one of the two nitrogen atoms in Gln is ${ }^{14} \mathrm{NH}_{4}{ }^{+}$, which can result from cellular nitrogen sources such as amino acids.

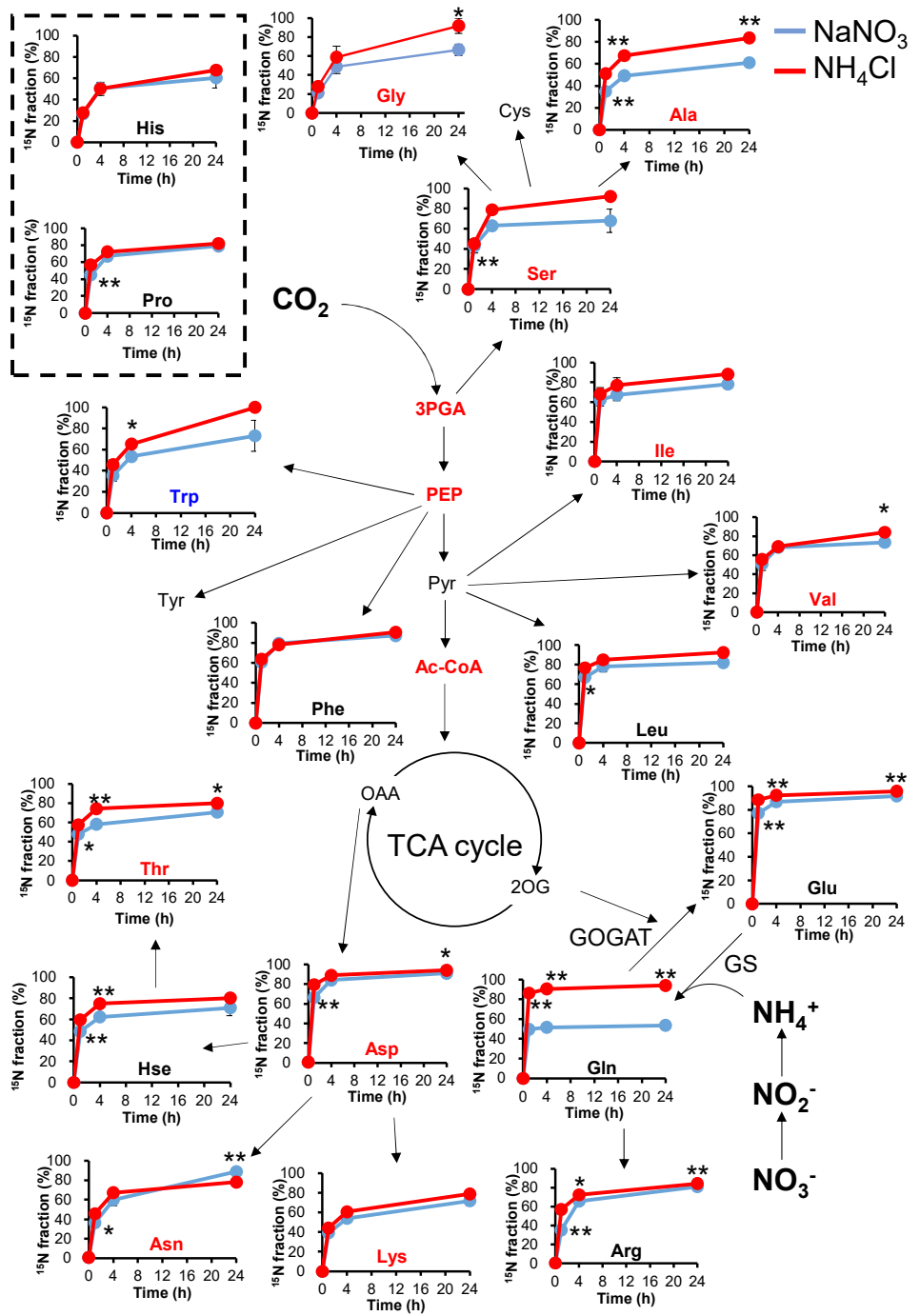

Figure 4. Analysis of ${ }^{15} \mathrm{~N}$ turnover under different nitrogen conditions. Synechocystis was cultivated in $\mathrm{Na}^{15} \mathrm{NO}_{3}$ or ${ }^{15} \mathrm{NH}_{4} \mathrm{Cl}$ media after cell inoculation. The ${ }^{15} \mathrm{~N}$ labeling rates of amino acids and their related metabolites were compared at each time point. Values represent the mean \pm standard deviation of three independent experiments. Blue lines, cultivation with $\mathrm{NaNO}_{3}$; red lines, cultivation with $\mathrm{NH}_{4} \mathrm{Cl}$. Red and blue characters indicate higher and lower amounts of metabolites when grown in $\mathrm{NH}_{4} \mathrm{Cl}$. Statistical significance was determined using Welch's $t$-test $\left({ }^{*}<0.05,{ }^{*}<0.01\right)$. 3PGA, 3-phosphoglycerate; Ac-CoA, acetyl-coenzyme A; Ala, alanine; Arg, arginine; Asp, aspartate; Asn, asparagine; Cys, cysteine; Glu, glutamate; Gln, glutamine; His, histidine; Hse, homoserine; Ile, isoleucine; Leu, leucine; Met, methionine; PEP, phosphoenolpyruvate; Phe, phenylalanine; Pro, proline; Pyr, pyruvate; Ser, serine; Thr, threonine; Trp, tryptophan; Tyr, tyrosine; Val, valine. 


\section{4. ${ }^{15} \mathrm{~N}$ Labelling Rate and Order in Glutamine Synthesis}

To elucidate the mechanism underlying the lower labeling rate of glutamine in the $\mathrm{NH}_{4} \mathrm{Cl}$ medium, the position of the ${ }^{15} \mathrm{~N}$-labeled nitrogen atom in the Gln molecule was examined using liquid chromatography-tandem mass spectrometry with the multiple reaction monitoring method (LC-MS/MS MRM) (Figure 5). ${ }^{15} \mathrm{~N}$ labeling conditions were the same as those for the experiments performed in Figure 4 (see Materials and Methods). The ${ }^{15} \mathrm{~N}$ labeling rate of Gln when cultured in $\mathrm{Na}^{15} \mathrm{NO}_{3}$ was almost constant for $24 \mathrm{~h}$ after Synechocystis inoculation (Figure 5A,B). On the other hand, when cultured in ${ }^{15} \mathrm{NH}_{4} \mathrm{Cl}$, the rate of ${ }^{15} \mathrm{~N}$ labeling of one of the two nitrogen atoms in Gln gradually decreased, and the unlabeled rate of Gln was $0.23 \%\left(2.5 \%\right.$ in the presence of $\left.\mathrm{Na}^{15} \mathrm{NO}_{3}\right)$. As shown in Figure 4, the total ${ }^{15} \mathrm{~N}$ labeling rate of the two nitrogen atoms in Gln was $71 \%$ in $\mathrm{Na}^{15} \mathrm{NO}_{3}$ and $89 \%$ in ${ }^{15} \mathrm{NH}_{4} \mathrm{Cl}$. Next, the position of the ${ }^{15} \mathrm{~N}$-labelled nitrogen atom in glutamine was investigated. The positions of the ${ }^{15} \mathrm{~N}$ labeling are described as positions 2 and 5 , which are the amino groups of the main and side chains (Figure 5E). Position 5 of Gln was preferentially labeled $1 \mathrm{~h}$ after Synechocystis was inoculated under culture conditions with $\mathrm{Na}^{15} \mathrm{NO}_{3}$. After an interval of $24 \mathrm{~h}$, the labeling rates of positions 2 and 5 became equal. On the other hand, in ${ }^{15} \mathrm{NH}_{4} \mathrm{Cl}$ medium, position 5 was always preferentially labeled during the period of $24 \mathrm{~h}$ after Synechocystis inoculation.
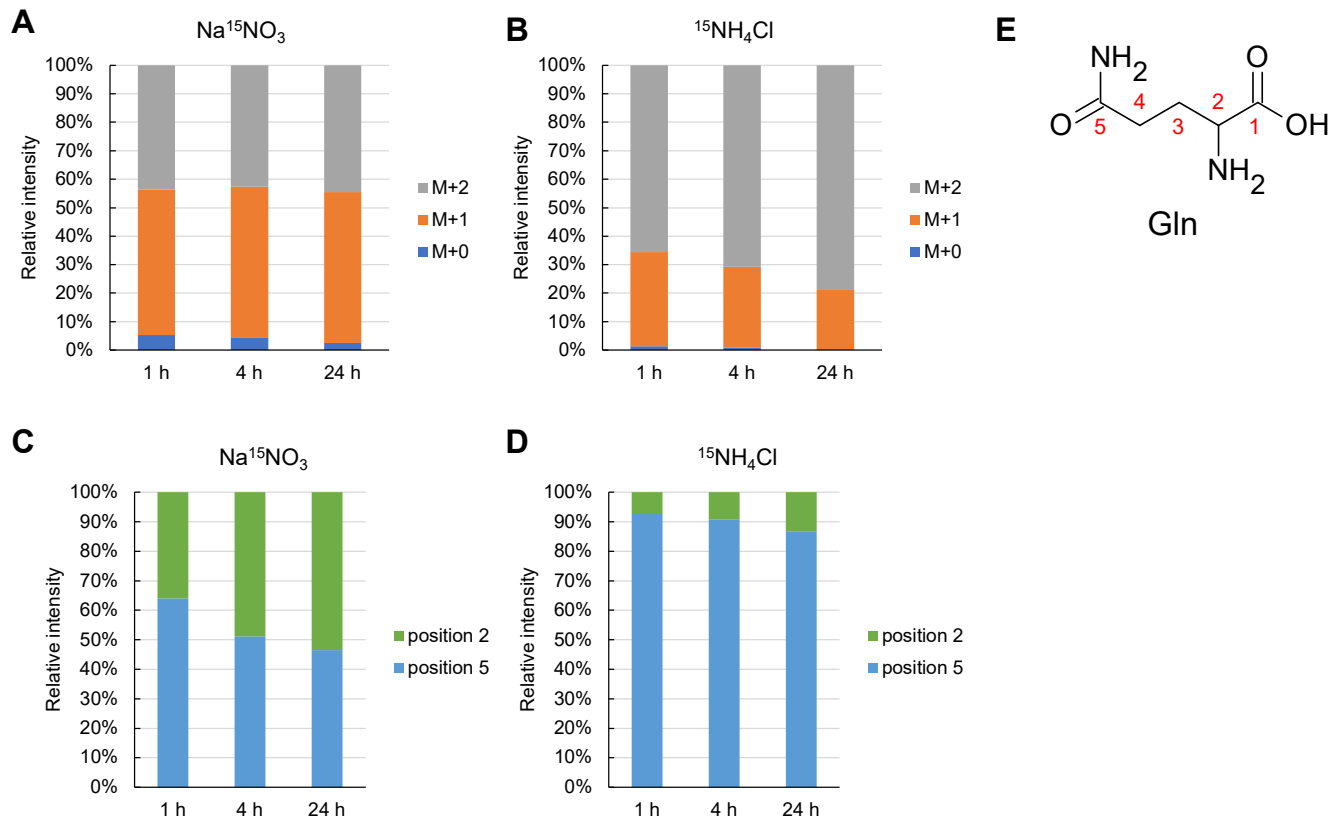

Figure 5. ${ }^{15} \mathrm{~N}$ labelling rate and its position in Gln. The ${ }^{15} \mathrm{~N}$ labeling rate and its position in Gln (glutamine) were examined by LC-MS/MS. A and B indicate the number of the ${ }^{15} \mathrm{~N}$-labelled $\mathrm{NH}_{2}$ group in glutamine and ${ }^{15} \mathrm{~N}$-labelled rate in each ${ }^{15} \mathrm{~N}$-labelled number of all Gln. (A), Cultivation in $\mathrm{Na}^{15} \mathrm{NO}_{3}$ medium; (B), Cultivation in ${ }^{15} \mathrm{NH}_{4} \mathrm{Cl}$ medium. (C,D) indicate the position of the two $\mathrm{NH}_{2}$ groups in Gln when one of the two was labeled at $\mathrm{M}^{+1}$ in (A-C), Cultivation in $\mathrm{Na}^{15} \mathrm{NO}_{3}$ medium; (D), Cultivation in ${ }^{15} \mathrm{NH}_{4} \mathrm{Cl}$ medium. (E), the position number in $\mathrm{Gln}$, as indicated in (C,D).

\subsection{Nitrogen Assimilation Rate by Glutamine Synthase and Glutamate Dehydrogenase}

From these results, the enzymatic activity for Gln synthesis was assumed to be affected by the type of nitrogen source. To test this hypothesis, we measured the catalytic activities of glutamine synthetase (GS) and glutamate dehydrogenase (GDH) from whole-cell lysates (Figure 6). The catalytic activity of GS was $1.1 \mathrm{U} / \mathrm{mg}$-protein when Synechocystis was grown in $\mathrm{NaNO}_{3}$ medium and $0.73 \mathrm{U} /$ mg-protein when grown in $\mathrm{NH}_{4} \mathrm{Cl}$ medium. In a previous report, the expression level of GS was higher in $\mathrm{NaNO}_{3}$ medium than in $\mathrm{NH}_{4} \mathrm{Cl}$ medium [14]. When considered with the results from this previous report, the difference in the catalytic activity of GS in Figure 6B reflects the difference in the expression level of GS 
itself. On the other hand, the activity of GDH was $3.5 \mathrm{mU} / \mathrm{mg}$-protein when Synechocystis was grown in $\mathrm{NH}_{4} \mathrm{Cl}$ medium and $2.3 \mathrm{mU} / \mathrm{mg}$-protein in $\mathrm{NaNO}_{3}$ medium; the catalytic activity of $\mathrm{GDH}$ in $\mathrm{NH}_{4} \mathrm{Cl}$ was higher than that in $\mathrm{NaNO}_{3}$.

A

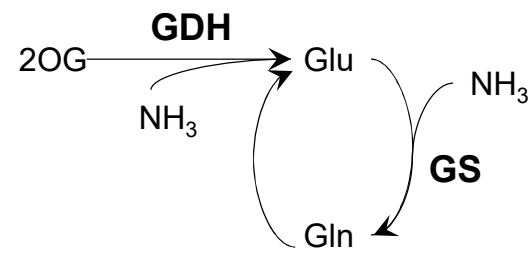

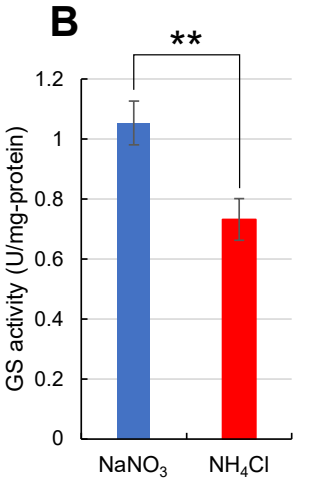

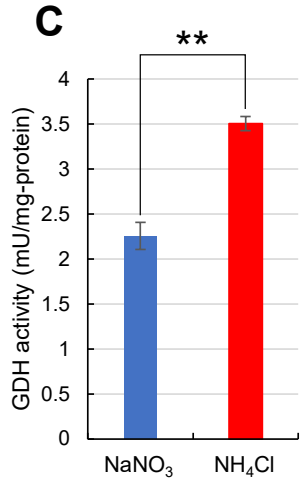

Figure 6. Catalytic activity of GS and GDH in whole cell lysates. The catalytic activity of GS and GDH in whole cell lysates of Synechocystis grown in different nitrogen sources was examined. Values represent the mean \pm standard deviation of three independent experiments. (A), Reaction scheme for each enzyme. (B), GS activity when grown in $\mathrm{NaNO}_{3}$ or $\mathrm{NH}_{4} \mathrm{Cl}$ media. (C), $\mathrm{GDH}$ activity when grown in $\mathrm{NaNO}_{3}$ or $\mathrm{NH}_{4} \mathrm{Cl}$ media. GS, glutamine synthase; $\mathrm{GDH}$, glutamate dehydrogenase. Statistical significance was determined using Welch's $t$-test $\left({ }^{* *}<0.01\right)$.

\section{Discussion}

\subsection{Different Assimilation Mechanisms for Nitrogen Depending on the Nitrogen Source}

In this study, we wished to elucidate the mechanisms by which Synechocystis grown under different nitrogen sources assimilates nitrogen, and more generally, to clarify how it responds to different nitrogen sources. Different types of nitrogen altered the growth rate, pool sizes of metabolites, and nitrogen assimilation rate of Synechocystis (Figures 1-5). In addition, the catalytic activities of GS and GDH were different for different types of nitrogen sources (Figure 6).

Based on the findings of this study, we propose a model for nitrogen assimilation by Synechocystis grown in different nitrogen sources (Figure 7). The model was prompted by ${ }^{15} \mathrm{~N}$ labeling experiments. In contrast to the assimilation of $\mathrm{NH}_{4}{ }^{+}$, Synechocystis was unable to assimilate $\mathrm{NO}_{3}-$ by itself and required an additional reducing power to convert it to $\mathrm{NH}_{4}{ }^{+}$(Figure 7A). This means that the reduction of $\mathrm{NO}_{3}{ }^{-}$appears to be the rate-limiting step for nitrogen assimilation. Therefore, at the beginning of the log phase, when there is sufficient photosynthetic reducing power, GS synthesizes Gln with ${ }^{15} \mathrm{NH}_{4}{ }^{+}$, resulting in the rapid labeling of the side chain of Gln with ${ }^{15} \mathrm{~N}$ (Reaction 1 in Figure 7A) [23]. This hypothesis is consistent with the finding that the preferentially ${ }^{15} \mathrm{~N}$-labeled nitrogen was in position 5 until $1 \mathrm{~h}$ later (Figure $5 \mathrm{C}$ ). Subsequently, the ${ }^{15} \mathrm{~N}$ labelled $\mathrm{NH}_{2}$ group is rapidly transferred to $2 \mathrm{OG}$ by GOGAT, resulting in two Glu molecules (Reaction 2 in Figure 7A) [24]. GS can also synthesize doubly ${ }^{15} \mathrm{~N}$-labeled Gln from newly reduced ${ }^{15} \mathrm{NH}_{4}{ }^{+}$and ${ }^{15} \mathrm{~N}$-labeled Glu (Reaction 1 in Figure 7A). Furthermore, ${ }^{15} \mathrm{~N}$-labeled Glu can be used as a nitrogen source in another pathway to generate another amino acid (Reaction 4 in Figure 7A). However, the reducing power gradually decreased as the light transmittance of the culture medium decreased during the transition from the early log phase (Figure 7A) to the late log phase (Figure 7B). It has been previously shown that light is necessary to reduce $\mathrm{NO}_{3}{ }^{-}$, and $\mathrm{Fd}$, which accepts the reducing power from the photosystem, reduces $\mathrm{NO}_{3}{ }^{-}$and $\mathrm{NO}_{2}{ }^{-}$to $\mathrm{NH}_{4}{ }^{+}[7,8,23,24]$. Thus, GS cannot use the newly reduced ${ }^{15} \mathrm{NH}_{4}{ }^{+}$but reuses ${ }^{14} \mathrm{NH}_{4}{ }^{+}$, which derived from amino acids due to the decrease in light (Figure 7B). As a result, Reaction 1 with ${ }^{15} \mathrm{NH}_{4}{ }^{+}$in Figure 7 would not occur. In fact, the ${ }^{15} \mathrm{~N}$ labeling rate of position 2 in Figure 5C gradually increased and became equal to that of position 5 after $24 \mathrm{~h}$. This can also explain why the ${ }^{15} \mathrm{~N}$ labeling rate of Gln was $50 \%$ (Figure 4 ) and $71 \%$ (Figure 5A). 


\section{A Early log phase under low $\mathrm{NH}_{4}{ }^{+}\left(\mathrm{NaNO}_{3}\right)$ conditions}
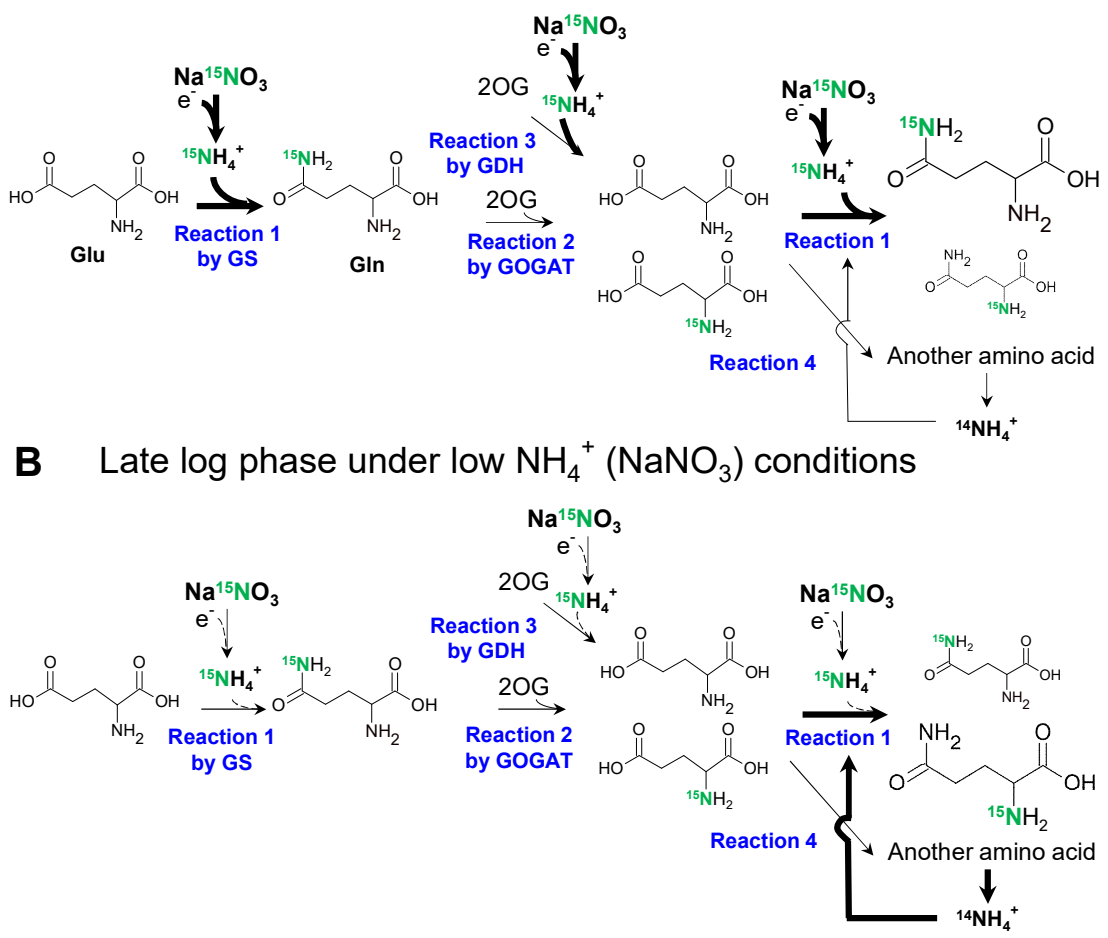

\section{High $\mathrm{NH}_{4}^{+}\left(\mathrm{NH}_{4} \mathrm{Cl}\right)$ conditions}

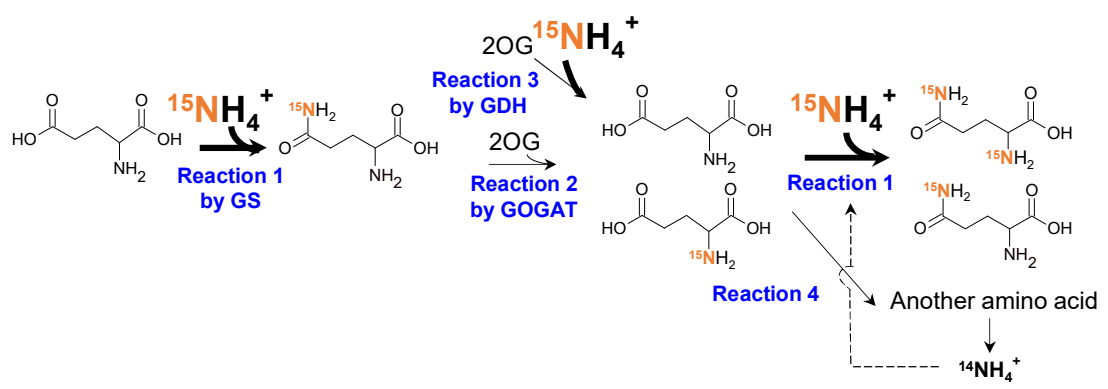

Figure 7. Reaction scheme with different nitrogen sources. The reaction scheme around the GSGOGAT cycle and the GDH pathway was constructed based on the results obtained. The bold arrows, thin arrows, and dotted arrows indicate the enhanced, not changed, and weakened fluxes in each reaction. (A), the reaction scheme during the early log phase when Synechocystis was grown in $\mathrm{Na}^{15} \mathrm{NO}_{3}$ medium; (B), the reaction scheme during late log phase when Synechocystis was grown in $\mathrm{Na}^{15} \mathrm{NO}_{3}$ medium; (C), the reaction scheme when Synechocystis was grown in ${ }^{15} \mathrm{NH}_{4} \mathrm{Cl}$ medium. The enlarged characters and molecular structure represent larger pool sizes of the molecule.

In contrast to $\mathrm{NO}_{3}{ }^{-}$, reducing power is not required to assimilate $\mathrm{NH}_{4}{ }^{+}$. Figure $5 \mathrm{D}$ illustrates that position 5 in Gln is always dominant throughout the $24 \mathrm{~h}$ period, and Figure $5 \mathrm{~B}$ indicates that $90 \%$ of nitrogen in all Gln molecules was labeled. The light conditions cannot be the rate-determining step to assimilate $\mathrm{NH}_{4}{ }^{+}$, and Reaction 1 in Figure $7 \mathrm{C}$ continues unless $\mathrm{NH}_{4}{ }^{+}$is lacking. Therefore, we assumed that the ${ }^{15} \mathrm{~N}$ labeling rate quickly approached $90 \%$, as shown in Figures 4 and $5 \mathrm{~B}$.

We also considered the possibility that the higher labeling rate with ${ }^{15} \mathrm{NH}_{4} \mathrm{Cl}$ in Figures 4 and 5 resulted from the higher activity of the GDH pathway, as shown in Figure 6C. However, such possibilities can be excluded because, in Figure 5D,E, position 2 should be preferentially labeled if the GDH pathway is activated when Synechocystis is cultivated in $\mathrm{NH}_{4} \mathrm{Cl}$ medium. GDH synthesizes Glu from $2 \mathrm{OG}$ and $\mathrm{NH}_{4}{ }^{+}$, suggesting that 
position 5 is not labeled [25] and GS activity was much higher than the activity of GDH (Figure 6).

The catalytic activity of GS was about 1000-fold higher than that of GDH in Figure 6B,C. For Synechocystis, GDH is not essential for growth under the high $\mathrm{CO}_{2}$ conditions [26]. In Escherichia coli, GDH supplies glutamine in the absence of a carbon source because GDH can produce it without ATP originating from carbon utilization [27]. This means that the high $\mathrm{CO}_{2}$ conditions which were adopted in our experiments might have caused the 1000-fold change differences between the catalytic activity of GS and GDH.

In this study, we found that the type of nitrogen sources can affect the metabolic profile of Synechocystis. The altered metabolic profile and labeling rate of Synechocytstis in Figures 2-5 when Synechocystis was grown in $\mathrm{NaNO}_{3}$ or $\mathrm{NH}_{4} \mathrm{Cl}$ media came from the availability of nitrogen. When Synechocystis was grown in $\mathrm{NH}_{4} \mathrm{Cl}$ medium, $\mathrm{NH}_{4}{ }^{+}$could be used without limitation unless $\mathrm{NH}_{4} \mathrm{Cl}$ was absent in the medium. On the other hand, additional reducing power is required to use $\mathrm{NaNO}_{3}$ because Synechocystis cannot use $\mathrm{NO}_{3}{ }^{-}$directly. This means that the amount of light transmitted, which is the source of reducing power, can be the rate-determining step. Thus, Synechocystis switch the main nitrogen sources from the external to internal nitrogen sources which arise from internal amino acids or proteins to produce glutamine during the change of growth stage when grown in $\mathrm{NaNO}_{3}$ medium. This switch between external and internal nitrogen sources might enable Synechocystis to grow at the constant rate. When grown in $\mathrm{NH}_{4} \mathrm{Cl}$ medium, the residual additional reducing power for Synechocystis to assimilate nitrogen enables it to supply reducing power to other pathways. The pool size of 3PGA increased and that of S7P and R5P decreased, as shown in Figure 3. The altered pool sizes of these metabolites might be caused by the enhanced $\mathrm{CBB}$ cycle, consuming the residual additional reducing power that was not used in the reduction of $\mathrm{NO}_{3}{ }^{-}$. Accordingly, the abundance of some metabolites in glycolysis and TCA cycle, and amino acids including 3PGA itself increased in Figures 2 and 3. We suspect the high cell growth rate was accomplished by higher abundance of those metabolites.

\subsection{The Choice of Nitrogen Source: $\mathrm{NO}_{3}{ }^{-}$or $\mathrm{NH}_{4}{ }^{+}$?}

So far, we revealed that Synechocystis switches the main nitrogen sources from the external to internal nitrogen sources during the change of growth stage when grown in $\mathrm{NaNO}_{3}$ medium and does not need to switch the nitrogen sources in $\mathrm{NH}_{4} \mathrm{Cl}$ medium. This speculation suggests that $\mathrm{NH}_{4}{ }^{+}$is ideal nitrogen sources for Synechocystis. However, there is a side effect of using $\mathrm{NH}_{4}{ }^{+}$as a nitrogen source. The electron transport rate in Synechocystis decreased in the presence of over $15 \mathrm{mM} \mathrm{NH}_{4} \mathrm{Cl}$ according to a previous report [11]. This means that excess $\mathrm{NH}_{4}{ }^{+}$can potentially inhibit photosynthesis in Synechocystis. In addition, GS-GOGAT cycle also requires the reducing power to assimilate nitrogen sources [1]. If the amount of $\mathrm{NH}_{4}{ }^{+}$supplied exceeds the reducing power from photosynthesis, the accumulation of $\mathrm{NH}_{4}{ }^{+}$would inhibit photosynthesis.

On the other hand, it is confirmed that there was no influence on photosynthesis over $15 \mathrm{mM} \mathrm{NaNO}_{3}$ in the same previous report. We guess the reason the excess amount of $\mathrm{NH}_{4}{ }^{+}$cannot accumulate in the cell because the production of $\mathrm{NH}_{4}{ }^{+}$is dependent on the availability of reducing power arisen from photosynthesis. This means that all the nitrogen assimilation pathway is dependent on the photosynthesis when grown in $\mathrm{NaNO}_{3}$, and it is beneficial for Synechocystis to perform the nitrogen assimilation in concert with photosynthesis and cell growth, preventing the excess accumulation of $\mathrm{NH}_{4}{ }^{+}$in the cell.

The proper type of nitrogen depends on the species of cyanobacteria, given that they can assimilate various types of nitrogen sources, such as $\mathrm{NO}_{3}{ }^{-}$and $\mathrm{NH}_{4}{ }^{+}$, as shown in this paper. $\mathrm{NH}_{4}{ }^{+}$stimulated the growth of Synechocystis, as shown in Figure 1. In contrast, it attenuated the growth of Arthrospira (Spirulina) sp. [12,16] and did not affect the growth of Microcystis aeruginosa NIES-843 [17]. The reasons for the differing responses of cyanobacteria species to different types of nitrogen sources remain unclear. However, we revealed that the enhancement of metabolite pool size and nitrogen turnover by $\mathrm{NH}_{4}{ }^{+}$ 
stimulated the growth of Synechocystis in this study. A comparison of the comprehensive metabolic profiles of these cyanobacteria species under different types of nitrogen might reveal the reasons for the different responses of cyanobacteria species.

\section{Materials and Methods}

\subsection{Strain and Cultivation Conditions}

Synechocystis sp. PCC 6803 strain was pre-cultivated in BG11 medium containing $20 \mathrm{mM}$ HEPES-KOH (pH 7.7) and $17.6 \mathrm{mM} \mathrm{NaNO}_{3}$ under $50 \mu \mathrm{mol}$ photons $\mathrm{m}^{-2} \mathrm{~s}^{-1}$ at $30{ }^{\circ} \mathrm{C}$ for 4 days, as described previously [18]. After pre-cultivation, Synechocystis was inoculated into modified BG11 medium containing $50 \mathrm{mM}$ HEPES- $\mathrm{KOH}(\mathrm{pH}$ 7.7) and $5 \mathrm{mM} \mathrm{NaNO}_{3}$ or $\mathrm{NH}_{4} \mathrm{Cl}\left(\mathrm{NaNO}_{3}\right.$ medium or $\mathrm{NH}_{4} \mathrm{Cl}$ medium) and cultivated under $1 \%$ $(v / v) \mathrm{CO}_{2}$ and $100 \mu \mathrm{mol}$ photons $\mathrm{m}^{-2} \mathrm{~s}^{-1}$ at $30^{\circ} \mathrm{C}$. The culture medium was recovered at the indicated times described below for further analysis. Statistical analysis was conducted using Welch's $t$-test $\left(*<0.05,{ }^{* *}<0.01\right)$.

\subsection{Measurement of the Intracellular Metabolite Concentration}

Extraction and analysis of the intracellular metabolites was performed as previously reported [18]. The procedure is described briefly. For the analysis of the intracellular metabolite concentration, the culture medium corresponding to $5 \mathrm{mg}$ of dry cell weight was recovered at $0,24,48$, and $72 \mathrm{~h}$ after inoculation with Synechocystis. After filtration, the collected cells were washed with $20 \mathrm{mM}\left(\mathrm{NH}_{4}\right)_{2} \mathrm{CO}_{3}$. The intracellular metabolite was extracted using pre-cooled methanol containing the internal standard, and the watersoluble phase was collected by mixing chloroform. The soluble protein was removed by filtration, and the resultant water phase containing the metabolite was evaporated under vacuum. The dried metabolites were dissolved in pure water and subjected to CE-MS analysis.

\section{3. ${ }^{15} \mathrm{~N}$-Metabolic Turnover Analysis}

The assimilation ratio of newly added nitrogen sources at each time point was determined using stable isotope ${ }^{15} \mathrm{~N}$-labelled $\mathrm{Na}^{15} \mathrm{NO}_{3}$ or ${ }^{15} \mathrm{NH}_{4} \mathrm{Cl}$. Synechocystis was transferred to the modified BG11 medium containing $5 \mathrm{mM} \mathrm{Na}^{15} \mathrm{NO}_{3}$ or ${ }^{15} \mathrm{NH}_{4} \mathrm{Cl} 24 \mathrm{~h}$ after inoculation and cultivated under $1 \%(v / v) \mathrm{CO}_{2}$ and $100 \mu \mathrm{mol}$ photons $\mathrm{m}^{-2} \mathrm{~s}^{-1}$ at $30^{\circ} \mathrm{C}$. The culture medium corresponding to $5 \mathrm{mg}$ of dry cell weight was recovered at 0,4 , and $24 \mathrm{~h}$, and the intracellular metabolites were analyzed by CE-MS as described above or by LC-MS/MS MRM. The procedure of sample preparation was the same as described above Section 4.2 (measurement of the intracellular metabolite concentration) and LC-MS/MS MRM analysis was performed by employing Nexera X2 high-performance liquid chromatography system and a LCMS-8060 triple quadrupole mass spectrometer (Shimadzu Corporation, Kyoto, Japan), as described previously [28]. The ${ }^{15} \mathrm{~N}$ labeling rate was calculated as performed in ${ }^{13} \mathrm{C}$ labeling experiments in previous reports [18]. The relative isotopomer abundance $\left(m_{i}\right)$ for each metabolite in which the $i^{15} \mathrm{~N}$ atoms were incorporated is calculated as follows:

$$
\begin{gathered}
m_{i}(\%)=\frac{M_{i}}{\sum_{j=0}^{n} M_{j}} \times 100 \\
{ }^{15} \mathrm{~N} \text { fraction }(\%)=\sum_{i=1}^{n} \frac{i \times m_{i}}{n}
\end{gathered}
$$

where $M_{i}$ represents the isotopomer abundance of metabolite incorporating $i^{15} \mathrm{~N}$ atoms, and $n$ is the number of nitrogen atoms in the metabolite. Statistical analysis was conducted using Welch's $t$-test $\left({ }^{*}<0.05,{ }^{* *}<0.01\right)$.

\subsection{Enzymatic Assay of Whole Cell Lysate}

Synechocystis cells that were cultured in the presence of $\mathrm{NaNO}_{3}$ or $\mathrm{NH}_{4} \mathrm{Cl}$ were collected by centrifugation $\left(3000 \times g, 4{ }^{\circ} \mathrm{C}, 10 \mathrm{~min}\right)$ and washed with nitrogen-free BG11 
medium. The cells were collected by centrifugation and resuspended in $60 \mathrm{mM}$ HEPES$\mathrm{KOH}$ ( $\mathrm{pH}$ 7.0). The suspended cells were disrupted by sonication, and the cell debris was removed by centrifugation $\left(20,000 \times g, 4{ }^{\circ} \mathrm{C}, 20 \mathrm{~min}\right)$. After centrifugation, the supernatant was collected, and the protein concentration was determined using the Takara BCA Protein assay kit (Takara, Shiga, Japan). Glutamine synthetase (GS) assays were performed as described previously with some modifications [15]. Fifteen microliters of whole cell lysate containing $16 \mu \mathrm{g}$ of protein was mixed well with $185 \mu \mathrm{L}$ reaction solution 1 containing

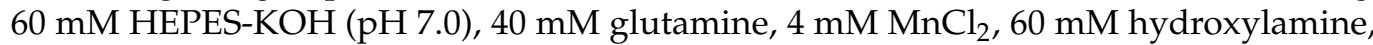
$1 \mathrm{mM}$ ADP, and $20 \mathrm{mM}$ sodium arsenate. Reaction solution 1 was incubated at $30{ }^{\circ} \mathrm{C}$ for $20 \mathrm{~min}$ and terminated by the addition of an equal volume of $\mathrm{FeCl}_{3}$ solution containing $0.5 \mathrm{M} \mathrm{HCl}, 247 \mathrm{mM} \mathrm{FeCl}_{3}$, and $196 \mathrm{mM}$ trichloroacetate. GS activity (units/mg protein) was calculated at an absorption wavelength of $500 \mathrm{~nm}$ to determine the amount of $\gamma$ glutamylhydroxamate. The glutamate dehydrogenase (GDH) assay was performed as described previously with some modifications [29]. Whole cell lysate containing $0.24 \mathrm{mg}$ of protein was mixed well with $875 \mu \mathrm{L}$ reaction solution 2 containing $85 \mathrm{mM}$ Tris- $\mathrm{HCl}$ ( $\mathrm{pH}$ 8.0), $10 \mathrm{mM} 2 \mathrm{OG}$, and $50 \mathrm{mM} \mathrm{NH}_{4} \mathrm{Cl}$. The catalytic reaction of GDH was initiated by the addition of $50 \mu \mathrm{L}$ of $0.2 \mathrm{mM} \mathrm{NADPH}$, and the decrease in NADPH at absorption at $340 \mathrm{~nm}$ was monitored using a spectrophotometer V-670 (JASCO, Tokyo, Japan) to calculate GDH activity (mUnits/mg-protein). Statistical analysis was conducted using Welch's $t$-test $\left(*<0.05,{ }^{* *}<0.01\right)$.

Supplementary Materials: The following are available online at https:/ /www.mdpi.com/article/ 10.3390/metabo11120867/s1, Figure S1: Growth curve of Synechocystis during 168 h in $\mathrm{NaNO}_{3}$ medium or $\mathrm{NH}_{4} \mathrm{Cl}$ medium under phototrophic conditions, Figure S2: Comparison of metabolic profiles in the Urea cycle. The pool sizes of some metabolites of the Urea cycle were examined. Blue lines, cultivation with $\mathrm{NaNO}_{3}$; Red lines, cultivation with $\mathrm{NH}_{4} \mathrm{Cl}$.; Arg, Arginine; CPS, Carbamoyl phosphate; Glu, Glutamate; Orn, Ornithine, Figure S3: ${ }^{15} \mathrm{~N}$ labelling rates of metabolites of the Urea cycle, ${ }^{15} \mathrm{~N}$ labelling rates of the Urea cycle was compared at each time point. Blue lines, cultivation with $\mathrm{NaNO}_{3}$; Red lines, cultivation with $\mathrm{NH}_{4} \mathrm{Cl}$; Arg, Arginine; CPS, Carbamoyl phosphate; Glu, Glutamate; Orn, Ornithine.

Author Contributions: Conceptualization, T.H.; methodology, T.H. and R.H.; formal analysis, K.I., A.M., M.M. and T.Y.; investigation, K.I. and A.M.; data curation, K.I., A.M., M.M. and T.Y.; writingoriginal draft preparation, K.I., Y.K., R.H. and T.H.; writing-review and editing, K.I., Y.K., R.H. and T.H.; supervision, A.K.; project administration, T.H.; funding acquisition, T.H. All authors have read and agreed to the published version of the manuscript.

Funding: This work was supported by the Mirai Program Grant Number JPMJMI19E4 and the Advanced Low Carbon Technology Research and Development Program (ALCA) [grant numbers JPMJAL1306 and JPMJAL1608] from the Japan Science and Technology Agency (JST) of the Ministry of Education, Culture, Sports, Science, and Technology (MEXT), Japan.

Institutional Review Board Statement: Not applicable.

Informed Consent Statement: Not applicable.

Data Availability Statement: Data is contained within the article or Supplementary Material.

Acknowledgments: This work was supported by the Advanced Low Carbon Technology Research and Development Program (ALCA) of the Japan Science and Technology Agency (JST), Ministry of Education, Culture, Sports, Science, and Technology (MEXT), Japan.

Conflicts of Interest: The authors declare no conflict of interest. 


\section{References}

1. Mills, L.A.; McCormick, A.J.; Lea-Smith, D.J. Current knowledge and recent advances in understanding metabolism of the model cyanobacterium Synechocystis sp. PCC 6803. Biosci. Rep. 2020, 40, BSR20193325. [CrossRef]

2. Zhang, H.; Liu, Y.; Nie, X.; Liu, L.; Hua, Q.; Zhao, G.P.; Yang, C. The cyanobacterial ornithine-ammonia cycle involves an arginine dihydrolase article. Nat. Chem. Biol. 2018, 14, 575-581. [CrossRef]

3. Masukawa, H.; Inoue, K.; Sakurai, H.; Wolk, C.P.; Hausinger, R.P. Site-directed mutagenesis of the anabaena sp. strain PCC 7120 nitrogenase active site to increase photobiological hydrogen production. Appl. Environ. Microbiol. 2010, 76, 6741-6750. [CrossRef]

4. Omata, T.; Andriesse, X.; Hirano, A. Identification and characterization of a gene cluster involved in nitrate transport in the cyanobacterium Synechococcus sp. PCC7942. MGG Mol. Genet. Genom. 1993, 236, 193-202. [CrossRef]

5. Montesinos, M.L.; Muro-Pastor, A.M.; Herrero, A.; Flores, E. Ammonium/methylammonium permeases of a cyanobacterium: Identification and analysis of three nitrogen-regulated amt genes in Synechocystis sp. PCC 6803. J. Biol. Chem. 1998, 273, 31463-31470. [CrossRef] [PubMed]

6. Veaudor, T.; Cassier-Chauvat, C.; Chauvat, F. Genomics of Urea Transport and Catabolism in Cyanobacteria: Biotechnological Implications. Front. Microbiol. 2019, 10, 1-14. [CrossRef]

7. Rubio, L.M.; Herrero, A.; Flores, E. A cyanobacterial narB gene encodes a ferredoxin-dependent nitrate reductase. Plant Mol. Biol. 1996, 30, 845-850. [CrossRef] [PubMed]

8. Flores, E.; Frías, J.E.; Rubio, L.M.; Herrero, A. Photosynthetic nitrate assimilation in cyanobacteria. Photosynth. Res. 2005, 83, 117-133. [CrossRef] [PubMed]

9. Herrero, A.; Flores, E. Genetic responses to carbon and nitrogen availability in Anabaena. Environ. Microbiol. 2019, $21,1-17$. [CrossRef] [PubMed]

10. Herrero, A.; Muro-Pastor, A.M.; Flores, E. Nitrogen control in cyanobacteria. J. Bacteriol. 2001, 183, 411-425. [CrossRef]

11. Drath, M.; Kloft, N.; Batschauer, A.; Marin, K.; Novak, J.; Forchhammer, K. Ammonia triggers photodamage of photosystem II in the cyanobacterium Synechocystis sp. strain PCC 6803. Plant Physiol. 2008, 147, 206-215. [CrossRef]

12. Rodrigues, M.S.; Ferreira, L.S.; Converti, A.; Sato, S.; Carvalho, J.C.M. Fed-batch cultivation of Arthrospira (Spirulina) platensis: Potassium nitrate and ammonium chloride as simultaneous nitrogen sources. Bioresour. Technol. 2010, 101, 4491-4498. [CrossRef]

13. Moore, L.R.; Post, A.F.; Rocap, G.; Chisholm, S.W. Utilization of different nitrogen sources by the marine cyanobacteria Prochlorococcus and Synechococcus. Limnol. Oceanogr. 2002, 47, 989-996. [CrossRef]

14. Reyes, J.C.; Muro-Pastor, M.I.; Florencio, F.J. Transcription of glutamine synthetase genes (glnA and glnN) from the cyanobacterium Synechocystis sp. strain PCC 6803 is differently regulated in response to nitrogen availability. J. Bacteriol. 1997, 179, 2678-2689. [CrossRef]

15. Merida, A.; Candau, P.; Florencio, F.J. Regulation of glutamine synthetase activity in the unicellular cyanobacterium Synechocystis sp. strain PCC 6803 by the nitrogen source: Effect of ammonium. J. Bacteriol. 1991, 173, 4095-4100. [CrossRef]

16. Deschoenmaeker, F.; Bayon-Vicente, G.; Sachdeva, N.; Depraetere, O.; Cabrera Pino, J.C.; Leroy, B.; Muylaert, K.; Wattiez, R. Impact of different nitrogen sources on the growth of Arthrospira sp. PCC 8005 under batch and continuous cultivation-A biochemical, transcriptomic and proteomic profile. Bioresour. Technol. 2017, 237, 78-88. [CrossRef]

17. Krausfeldt, L.E.; Farmer, A.T.; Castro, H.F.; Boyer, G.L.; Campagna, S.R.; Wilhelm, S.W. Nitrogen flux into metabolites and microcystins changes in response to different nitrogen sources in Microcystis aeruginosa NIES-843. Environ. Microbiol. 2020, 22, 2419-2431. [CrossRef]

18. Hasunuma, T.; Matsuda, M.; Kondo, A. Improved sugar-free succinate production by Synechocystis sp. PCC 6803 following identification of the limiting steps in glycogen catabolism. Metab. Eng. Commun. 2016, 3, 130-141. [CrossRef]

19. Hasunuma, T.; Kikuyama, F.; Matsuda, M.; Aikawa, S.; Izumi, Y.; Kondo, A. Dynamic metabolic profiling of cyanobacterial glycogen biosynthesis under conditions of nitrate depletion. J. Exp. Bot. 2013, 64, 2943-2954. [CrossRef] [PubMed]

20. Osanai, T.; Oikawa, A.; Shirai, T.; Kuwahara, A.; Iijima, H.; Tanaka, K.; Ikeuchi, M.; Kondo, A.; Saito, K.; Hirai, M.Y. Capillary electrophoresis-mass spectrometry reveals the distribution of carbon metabolites during nitrogen starvation in Synechocystis sp. PCC 6803. Environ. Microbiol. 2014, 16, 512-524. [CrossRef] [PubMed]

21. Kinnel, R.B.; Esquenazi, E.; Leao, T.; Moss, N.; Mevers, E.; Pereira, A.R.; Monroe, E.A.; Korobeynikov, A.; Murray, T.F.; Sherman, D.; et al. A Maldiisotopic Approach to Discover Natural Products: Cryptomaldamide, a Hybrid Tripeptide from the Marine Cyanobacterium Moorea producens. J. Nat. Prod. 2017, 80, 1514-1521. [CrossRef] [PubMed]

22. May, D.S.; Crnkovic, C.M.; Krunic, A.; Wilson, T.A.; Fuchs, J.R.; Orjala, J.E. 15N Stable Isotope Labeling and Comparative Metabolomics Facilitates Genome Mining in Cultured Cyanobacteria. ACS Chem. Biol. 2020, 15, 758-765. [CrossRef]

23. Grant, B.R.; Turner, I.M. Light-stimulated nitrate and nitrite assimilation in several species of algae. Comp. Biochem. Physiol. 1969, 29, 995-1004. [CrossRef]

24. Manzano, C.; Candau, P.; Gomez-Moreno, C.; Relimpio, A.M.; Losada, M. Ferredoxin-dependent photosynthetic reduction of nitrate and nitrite by particles of anacystis nidulans. Mol. Cell. Biochem. 1976, 10, 161-169. [CrossRef] [PubMed]

25. Prakash, P.; Punekar, N.S.; Bhaumik, P. Structural basis for the catalytic mechanism and -ketoglutarate cooperativity of glutamate dehydrogenase. J. Biol. Chem. 2018, 293, 6241-6258. [CrossRef]

26. Chávez, S.; Lucena, J.M.; Reyes, J.C.; Florencio, F.J.; Candau, P. The presence of glutamate dehydrogenase is a selective advantage for the cyanobacterium Synechocystis sp. strain PCC 6803 under nonexponential growth conditions. J. Bacteriol. 1999, 181, 808-813. [CrossRef] 
27. Helling, R.B. Pathway choice in glutamate synthesis in Escherichia coli. J. Bacteriol. 1998, 180, 4571-4575. [CrossRef] [PubMed]

28. Takenaka, M.; Yoshida, T.; Hori, Y.; Bamba, T.; Mochizuki, M.; Vavricka, C.J.; Hattori, T.; Hayakawa, Y.; Hasunuma, T.; Kondo, A. An ion-pair free LC-MS/MS method for quantitative metabolite profiling of microbial bioproduction systems. Talanta 2021, 222, 121625. [CrossRef]

29. Florencio, F.J.; Marqués, S.; Candau, P. Identification and characterization of a glutamate dehydrogenase in the unicellular cyanobacterium Synechocystis PCC 6803. FEBS Lett. 1987, 223, 37-41. [CrossRef] 